\title{
Radiation-induced optic neuropathy after pencil beam scanning proton therapy for skull-base and head and neck tumours
}

\author{
${ }^{1}$ MELPOMENI KOUNTOURI, MBChB MSc, 'ALESSIA PICA, MD, 'MARC WALSER, MD, ${ }^{1}$ FRANCESCA ALBERTINI, PhD, \\ 'ALESSANDRA BOLSI, MSc, 'ULRIKE KLIEBSCH, PhD, 'BARBARA BACHTIARY, MD, ${ }^{1}$ CHRISTOPHE COMBESCURE, PhD, \\ ${ }^{1,3}$ ANTONY J. LOMAX, PhD, ${ }^{1}$ RALF SCHNEIDER, MD and ${ }^{1,4,5}$ DAMIEN CHARLES WEBER, MD \\ ${ }^{1}$ Center for Proton Therapy, Paul Scherrer Institute, ETH Domain, CH-5232, Villigen, Switzerland \\ ${ }^{2}$ Service d'Epidemiologie Clinique, Hôpitaux Universitaire de Genève, CH 12011 Geneva, Geneva, Switzerland \\ ${ }^{3}$ Department of Physics, ETH, Zürich, Switzerland \\ ${ }^{4}$ University of Bern, Bern, Switzerland \\ ${ }^{5}$ University of Zürich, Zürich, Switzerland
}

Address correspondence to: ProfDrmed Damien Charles Weber

E-mail: damien.weber@psi.ch

Objective: To assess the radiation-induced optic neuropathy (RION) prevalence, following high dose pencil beam scanning proton therapy (PBSPT) to skull base and head and neck (H\&N) tumours

Methods: Between 1999 and 2014, 216 adult patients, median age 47 years (range, 18-77), were treated with PBS PT for skull base or H\&N malignancies, delivering $\geq 45$ $G_{\text {RBE }}$ to the optic nerve(s) (ON) and/or optic chiasma (OC). The median administered dose to the planning target volume was $74.0 \mathrm{~Gy}_{\mathrm{RBE}}$ (range, 54.0-77.4). The median follow-up was 5.3 years (range, 0.8-15.9).

Results: RION was observed in 14 (6.5\%) patients at a median time of 13.2 months (range, 4.8-42.6) following PBSPT. Most (92.9\%) of RION were symptomatic. Most affected patients (11/14; 79\%) developed unilateral toxicity. Grade 4, 3, 2 and 1 toxicity was observed in 10, 2, 1 and 1 patients, respectively. On univariate analyses,

\section{INTRODUCTION}

Treatment of aggressive intracranial tumours often require high radiation doses, the delivery of which can be limited by the dose constraints to neighbouring organs at risk (OARs), such as the optic nerves and the chiasma. Exceeding the radiation tolerance of these optic structures can result in radiation-induced optic neuropathy (RION), which presents usually as painless monocular loss of vision in presence of optic nerve injury or bilateral vision loss if the optic chiasma is involved. RION is in essence due to ischaemia to the optic apparatus caused by the occlusive obstruction of the blood supply, hence leading to optic atrophy and consequential partial loss of function. ${ }^{1,2}$ age $(<70$ vs $\geq 70$ years; $p<0.0001)$, hypertension $(p=$ $0.0007)$ and tumour abutting the optic apparatus ( $p$ $=0.012$ ) were associated with RION. OC'S V6O Gy RBE was of border line significance $(p=0.06)$. None of the other evaluated OC-ON dose/volume metrics (Dmax, Dmean, V40-60) were significantly associated with this complication.

Conclusion: These data suggest that high-dose PBS PT for skull base and H\&N tumours is associated with a low prevalence of RION. Caution should be however exercised when treating elderly/hypertensive patients with tumours abutting the optic apparatus.

Advances in knowledge: This is the first study reporting the risk of developing RION following proton therapy with $\mathrm{PBS}$ technique, demonstrating the safety of this treatment.

In order to reduce the risk of RION particle beam therapy using protons has been employed to deliver high radiation doses to tumours in close vicinity to the optic apparatus. ${ }^{3-5}$ Particles have a finite range in tissue and a zero exit dose rendering them an advantageous treatment option in such challenging cases. Furthermore, using pencil beam scanning (PBS), a delivery technique clinically developed at the Paul Scherrer Institute (PSI), optimizes proximal dose delivery compared to passive scattered protons. ${ }^{6-8}$

The aim of this study is to assess the risk of RION in patients treated uniquely with PBSPT to skull base or head and neck $(\mathrm{H} \& \mathrm{~N})$ tumours and to assess potential risk factors for visual toxicity. 


\section{METHODS AND MATERIALS}

Patient and tumour characteristics

The PSI patient database was queried to identify all adult $(\geq 18$ years) patients receiving PBSPT with curative intent for a tumour of the base of skull or the H\&N between 1999 and 2014 and who received $\geq 45 \mathrm{~Gy}_{\mathrm{RBE}}$ to the optic apparatus. This dose level was chosen because it is very unlikely that patients present any visual toxicity under this cut-off dose. ${ }^{9}$ Patients who were diagnosed with a tumour of the optic apparatus were not included in the study, neither patients who had received chemotherapy prior or concomitant to PT. Hence, 216 consecutive patients were identified. Of these, 44 (20.9\%) patients presented with visual deficits (visual acuity and/or visual field deficits) prior to PT. All patients underwent ophthalmological assessment, including fundoscopy and visual fields prior to PT and yearly thereafter.

The type of tumours is summarized in Table 1. The median patient age at PT was 47 years [interquartile range (IQR), 35.860 ], with most (83.3\%) patients being less than 65 years old, with slightly more females than males (51.4\% vs $48.6 \%$ ). The other treatment characteristics are detailed in Table 1.

\section{Treatment characteristics}

All but one patient with meningioma underwent biopsy prior to PT and most of them underwent a partial resection $(n=201$; 93.1\%), only $14(6.5 \%)$ patients underwent total resection. This was followed by adjuvant PT in 164 patients (75.9\%) while the other patients $(n=52 ; 24.1 \%)$ received salvage proton therapy following tumour recurrence. The dose/volume metrics on the optic apparatus are detailed in Table 2. The median postoperative volume of the residual disease as identified on the planning computed tomography and postoperative MRI, and defining the gross tumour volume (GTV), was $25.6 \mathrm{~cm}^{3}$ (range 0.0-205.3). When a dose boost was planned this was delivered sequentially. The highest mean dose (Dmean) and maximum dose (Dmax) of the two optic nerves (ONs) were used in order to calculate the median Dmean and Dmax of the optic nerves.

The contours of all the structures for each patient included in the study were reviewed by two radiation oncologists. There was no PRV around the optic apparatus. Planning target volume (PTV) was created from a $5 \mathrm{~mm}$ expansion from CTV. The treatments of these brain/skull base tumour and H\&N cancer patients were very different between them, hence no specific technical details are provided here. Treatment plans, single-field uniform dose (SFUD) plans followed by intensity modulated proton therapy (IMPT) plans, were optimized to achieve the best coverage of the GTV, while respecting the dose constraints to the OARs. The planning approach has been rather robust over time, i.e. starting with an SFUD paradigm using usually a 3-4 ("STAR") field arrangement. The boosting paradigm is usually performed using IMPT (i.e. delivering a two anterior oblique and two posterior oblique field arrangement). Especially so for H\&N cancers, treated with beams crossing cavities, anatomical changes were routinely checked. Despite anatomic variations seen in our patients, clinically delivered plans have been found to be rather robust to anatomic changes, with replanning being deemed necessary in only a small number of cases (approximately $5 \%$ of
Table 1. Patients and treatment characteristics $(n=216)$ of skull-base and head and neck tumours treated with pencil beam scanning proton therapy

\begin{tabular}{|c|c|}
\hline Parameter & $\begin{array}{c}\text { Total } \\
\begin{array}{c}N=216 \\
(\%)\end{array}\end{array}$ \\
\hline \multicolumn{2}{|l|}{ Patient characteristics } \\
\hline \multicolumn{2}{|l|}{ Age at PT (Years) } \\
\hline Median (IQR) & $47(35.8-60)$ \\
\hline \multicolumn{2}{|l|}{ Gender } \\
\hline Male (\%) & $105(48.6)$ \\
\hline Female (\%) & $111(51.4)$ \\
\hline \multicolumn{2}{|l|}{ Age $\geq 70$ years } \\
\hline Yes (\%) & $8(3.7)$ \\
\hline No (\%) & $208(96.3)$ \\
\hline \multicolumn{2}{|l|}{ Diabetes } \\
\hline Yes (\%) & $17(7.9)$ \\
\hline No (\%) & $176(81.5)$ \\
\hline Unknown & $23(10.6)$ \\
\hline \multicolumn{2}{|l|}{ Arterial hypertension } \\
\hline Yes (\%) & $51(23.6)$ \\
\hline No (\%) & $142(65.8)$ \\
\hline Unknown & $23(10.6)$ \\
\hline \multicolumn{2}{|l|}{ Hypercholesterolemia } \\
\hline Yes (\%) & $16(7.4)$ \\
\hline No (\%) & $177(81.9)$ \\
\hline Unknown & $23(10.7)$ \\
\hline \multicolumn{2}{|l|}{ Smoking history } \\
\hline Yes (\%) & $49(22.7)$ \\
\hline No (\%) & $120(55.6)$ \\
\hline Unknown & $47(21.7)$ \\
\hline \multicolumn{2}{|l|}{ Visual deficit at start of PT } \\
\hline Yes (\%) & $44(20.3)$ \\
\hline No (\%) & $167(77.3)$ \\
\hline Unknown & $5(2.3)$ \\
\hline \multicolumn{2}{|l|}{ Tumour characteristics } \\
\hline \multicolumn{2}{|l|}{ Histology $(n=215)$} \\
\hline Chordoma (\%) & $114(52.8)$ \\
\hline Chondrosarcoma (\%) & $48(22.2)$ \\
\hline Meningioma WHO G1-3 (\%) & $39(18.1)$ \\
\hline Adenoid cystic carcinoma (\%) & $7(3.2)$ \\
\hline Pituitary gland tumours (\%) & $2(0.9)$ \\
\hline Other $(\%)$ & $6(2.8)$ \\
\hline $\operatorname{GTV}\left(\mathrm{cm}^{3}\right)$ & \\
\hline
\end{tabular}

(Continued) 
Table 1. (Continued)

\begin{tabular}{|c|c|}
\hline Parameter & $\begin{array}{c}\text { Total } \\
N=216 \\
(\%)\end{array}$ \\
\hline Median & 25.9 \\
\hline (range) & $(1.8-205.3)$ \\
\hline \multicolumn{2}{|c|}{$\begin{array}{l}\text { Tumour involvement with optic } \\
\text { pathways (at beginning of PT) }\end{array}$} \\
\hline Yes (\%) & $68(31.5)$ \\
\hline No (\%) & $148(68.5)$ \\
\hline \multicolumn{2}{|l|}{ Treatment characteristics } \\
\hline \multicolumn{2}{|l|}{ PT } \\
\hline Adjuvant (\%) & $164(75.9)$ \\
\hline Salvaged (\%) & $52(24.1)$ \\
\hline \multicolumn{2}{|c|}{$\begin{array}{l}\text { Median administered dose (range) } \\
{\left[\mathrm{Gy}_{\mathrm{RBE}}\right]}\end{array}$} \\
\hline $\mathrm{D}_{\max } \mathrm{ON}$ (range) [Gy $\left.\mathrm{GBE}_{\mathrm{RB}}\right]$ & $59.5(18-76.1)$ \\
\hline $\mathrm{D}_{\text {mean }} \mathrm{ON}$ (range) [Gy $\left.\mathrm{GBE}_{\mathrm{RBE}}\right]$ & $35.5(1.7-67.8)$ \\
\hline V45 ON (range) [ml] & $0.43(0-1.8)$ \\
\hline V60 ON (range) [ml] & $0(0-1.14)$ \\
\hline $\mathrm{D}_{\max } \mathrm{OC}\left(\right.$ range) $\left[\mathrm{Gy} \mathrm{RBE}_{\mathrm{RE}}\right]$ & $58.8(37.6-66.5)$ \\
\hline $\mathrm{D}_{\text {mean }} \mathrm{OC}$ (range) $\left[\mathrm{Gy}_{\mathrm{RBE}}\right]$ & $50.5(3.7-62.6)$ \\
\hline V45 OC (range) [ml] & $0.85(0-2.4)$ \\
\hline V60 OC (range) [ml] & $0(0-1.3)$ \\
\hline
\end{tabular}

GTV, gross tumour volume; IQR, interquartile range; OC, optic chiasma; ON, optic nerve; PT, proton therapy; RBE, relative biological effectiveness.

all our patients treated). ${ }^{10}$ The median administered dose was 74 (IQR: 70-74) Gy $\mathrm{V}_{\mathrm{RBE}}$ at 1.8-2.0 Gy $\mathrm{RBE}_{\mathrm{RB}}$ per fraction.

\section{Follow-up evaluation}

Clinical and radiological follow-up with an MRI \pm CT was scheduled at 3 to 6 month intervals in the first 2-3 years after PT and annually thereafter.

RION was diagnosed clinically in non-recurring patients in the presence of painless progressive visual acuity loss with a visual field defect and abnormal visual evoked potentials and/or also in presence of ophthalmoscopic findings, such as optic disc pallor on fundoscopy. An annual ophthalmological examination was recommended following $\mathrm{PT}$ and was organized at the discretion of the referring centres. In addition, MRI gadolinium-enhanced imaging was analyzed for each patient and RION is diagnosed in the presence of a discrete region of enhancement of the prechiasmatic optic nerve or of the chiasma.

Patients who had tumour recurrence involving the optic apparatus or other diseases potentially leading to visual loss were not diagnosed with RION. The Response Evaluation Criteria in Solid
Tumours (RECIST v1.1) were used to evaluate tumour response to treatment.

The National Cancer Institute Common Terminology Criteria for Adverse Events v. 4.03 grading system was used to classify optic nerve toxicity.

\section{Statistical analysis}

Patient, tumour and treatment characteristics presented as categorical data were analysed using the $\chi^{2}$ or Fisher's exact test, if the expected count was $\leq 5$, in order to compare patients with and without optic toxicity. For continuous data independent $t$ test was applied for this comparison.

Kaplan-Meier curves were used to evaluate optic toxicity-free survival (TFS), local control (LC) and overall survival (OS). Survivals were calculated from the end of PT. When assessing TFS and LC, patients were censored at the time of death of the last follow-up. Local progression was defined as an increase in tumour burden by more than $20 \%$ in sum from nadir. Stable disease was defined as lack of disease progression clinically or radiologically. Associations between factors and survivals were investigated using log-rank test. In addition, univariate Cox regression models were used to assess the hazard ratio for the associations. Due to the low number of optic toxicity events multivariate analysis was not feasible.

Differences were considered statistically significant at the $p$ $<0.05$ level, all tests being two-sided. Statistical analyses were performed using R software, v. 3.3.1 (R Foundation for Statistical Computing, Vienna, Austria, www.cran.r-project.org).

\section{RESULTS}

Following a median follow-up of 5.3 years (range, 0.8-15.9), the 3 - and 5 year OS rates were $99 \% \pm 1.4$ and $90.7 \% \pm 4.3$ respectively while the 3 - and 5 year LC rates were $91.8 \% \pm$ 3.7 and $84.3 \% \pm 5.1$ respectively. Although the dose delivered to the optic apparatus was high, only $14(6.5 \%)$ patients were diagnosed with new RION during the follow-up period. The median Dmax was $59.5 \mathrm{~Gy}_{\mathrm{RBE}}$ to the $\mathrm{ON}$ and $58.8 \mathrm{~Gy}_{\mathrm{RBE}}$ to the OC while the median Dmean was $35.5 \mathrm{~Gy}_{\mathrm{RBE}}$ and $50.5 \mathrm{~Gy}_{\mathrm{RBE}}$ respectively. Most (92.9\%) of the RIONs were symptomatic. The median time from PT to RION was 13.2 months (range, 4.8-42.6) and the 5 year RION-free survival was $93.3 \%$ (90.0$96.8 \%$; Figure 1). Of note, there was no toxicity recorded after 48 months following PT.

The majority of patients $(n=11 ; 78.6 \%)$ with RION were unilaterally affected, with eight patients (72.7\%) diagnosed with Grade 4 toxicity, two patients (18.2\%) with Grade 3 toxicity and one patient $(9.1 \%)$ with Grade 1 toxicity. Table 2 details the observed RIONs. Of the three $(21.4 \%)$ patients presenting RION bilaterally, two patients had Grade 4 toxicities at least on one side. The third patient had a Grade 1 toxicity in the left eye and Grade 2 in the right eye (Table 2).

Apart from V54 ON, all other patients' dose/volume metrics of the optic apparatus were higher for patients with RION 


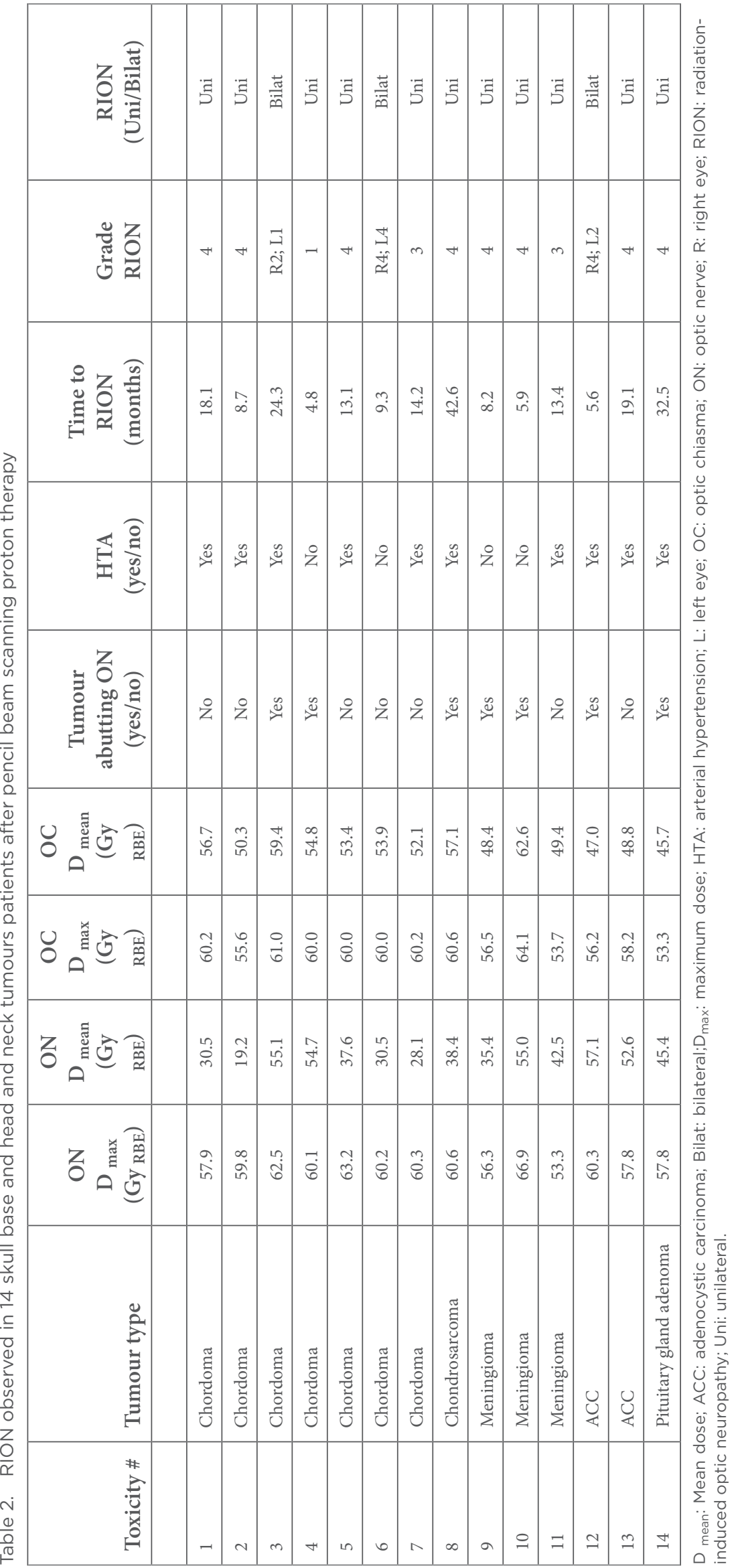


Figure 1. RION-free survival curve following proton therapy. In total 14 patients were diagnosed with RION during the follow-up period. All patients presented within the first 4 years following the end of proton therapy while there were no new events thereafter. RION,radiation-induced optic neuropathy.

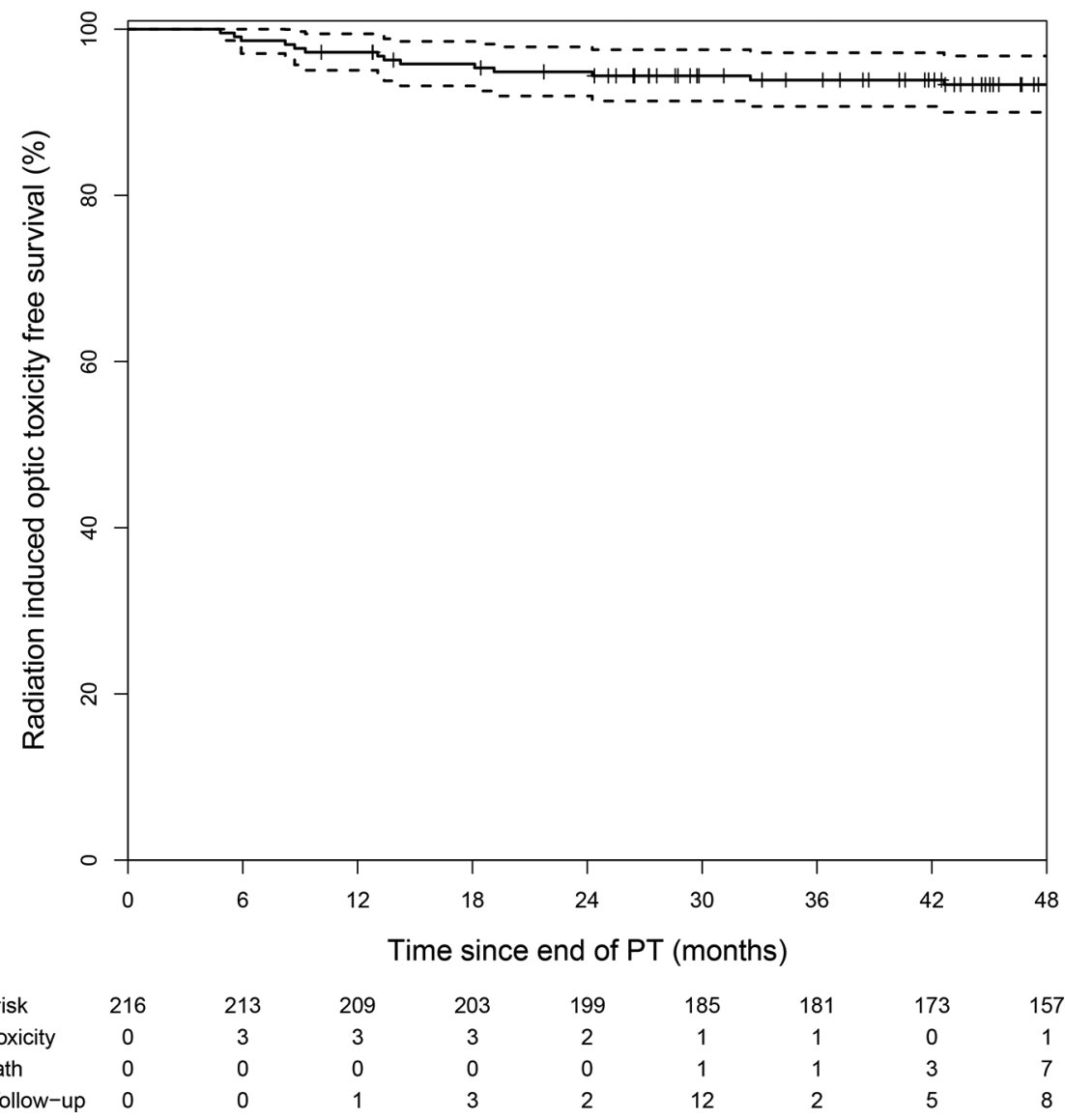

as compared to those with no toxicity (Table 3), although this incremental dose delivered to the optic apparatus was not statistically significant (Table 4 ). On log-rank analysis (Table 4 ), older ( $\geq 70$ years) patients were significantly $(p<$ $0.001)$ more at risk of presenting RION during follow-up. Likewise, the likelihood of having a RION was significantly ( $p$ $<0.001$ ) increased in patient with hypertension prior to PT. Those patients with tumour abutting or compressing the optic apparatus prior to PT were significantly $(p=0.006)$ more at risk for this complication. Likewise, patients presenting an $\mathrm{ON}$ inside the planning treatment volume were at higher risk ( $p=$ $0.04)$ for RION. Apart from V60 for the ON $(p=0.09)$ and OC $(p=0.05)$ for which a trend towards statistical significance was observed, none of the other dose/volume metrics were associated with RION. There was also a statistical trend toward significance for diabetes $(p=0.08)$ and hypercholesterolemia $(p=0.07)$. Gender $(p=0.11)$, histology $(p=0.10)$, history of smoking ( $p=0.26)$, GTV ( $p=0.28)$, visual deficit prior to PT $(p=0.19)$, number of surgeries prior to PT $(p=0.61)$, CTV $(p=0.79)$ and PTV $(p=0.97)$ were not associated with RION (Table 4).

On univariate analysis, only age $(<70 v s . \geq 70$ years; $p<0.0001)$, hypertension $(p=0.0007)$ and tumour abutting the optic apparatus $(p=0.012)$ retained statistical significance (Table 4$)$. Of note, the volume of the $\mathrm{ON}$ and $\mathrm{OC}$ receiving $60 \mathrm{~Gy} \mathrm{RBE}$ was of borderline significance (Table 4).

\section{DISCUSSION}

Although patients were at risk of having visual toxicity, our data suggest that the prevalence of RION is low following high dose PBSPT to skull base and head and neck tumours. This is the first study to our knowledge to report specifically on the prevalence of optic nerve toxicity in a large cohort of patients at risk of visual toxicity treated with PBSPT at one center.

Our results are in line with current literature reporting low incidence rates of RION in patients treated with PT and/ or photon therapy. It is undisputable that this complication increases with radiation dose. For fractionated proton therapy, one of the first studies to report on the visual outcomes following accelerated fractionated radiation with photons/ protons included 36 patients treated for advanced sinonasal malignancies, where the Boston group reported optic neuropathy observed in only 1 of the 13 patients presenting with late visual/ocular toxicity. ${ }^{11}$ It is important to mention that visual toxicity is usually reported in series assessing the general outcome of patients receiving radiation therapy with photons (non-IMRT) combined with protons in certain cases. There is only one IMRT series ${ }^{12}$ that reported the visual outcome and 
Table 3. Dose/volume metrics of patients with and without RION after pencil beam scanning PT

\begin{tabular}{|l|c|c|c|c|c|c|}
\hline & \multicolumn{2}{|c|}{$\begin{array}{c}\text { Patients without } \\
\text { RION (n= 202) }\end{array}$} & \multicolumn{2}{c|}{$\begin{array}{c}\text { Patients with } \\
\text { RION (n= 14) }\end{array}$} \\
\hline Variable & $\mathrm{N}=$ & Median & IQR & N= & Median & IQR \\
\hline Administered dose(Gy RBE) & 184 & 74 & $70-74$ & 14 & 73 & $65.5-74$ \\
\hline Total \# fractions & 202 & 37 & $35-37$ & 14 & 37 & $32.8-37$ \\
\hline Duration PT (days) & 202 & 51 & $49-55$ & 14 & 51.5 & $48.8-55.5$ \\
\hline Dmax OC & 202 & 58.8 & $55.2-60$ & 14 & 60 & $56.2-60.2$ \\
\hline Dmean OC & 202 & 50.4 & $43.9-53.8$ & 14 & 52.8 & $48.9-65.3$ \\
\hline V45 OC $(m l)$ & 202 & 0.9 & $0.5-1.2$ & 14 & 0.9 & $0.6-1.0$ \\
\hline V50 OC $(m l)$ & 202 & 0.6 & $0.3-1.0$ & 14 & 0.6 & $0.4-0.9$ \\
\hline V54 OC $(m l)$ & 202 & 0.3 & $0.04-0.6$ & 14 & 0.5 & $0.1-0.8$ \\
\hline Dmax ON & 202 & 59.4 & $55.4-60.4$ & 14 & 60.2 & $57.8-60.6$ \\
\hline Dmean ON & 202 & 34.9 & $21.6-45.7$ & 14 & 40.4 & $31.7-51.2$ \\
\hline V45 ON $(m l)$ & 202 & 0.4 & $0.2-0.7$ & 14 & 0.6 & $0.4-1.0$ \\
\hline V50 ON $(m l)$ & 202 & 0.3 & $0.1-0.7$ & 14 & 0.4 & $0.2-0.8$ \\
\hline V54 ON $(m l)$ & 202 & 0.2 & $0.04-0.3$ & 14 & 0.2 & $0.2-0.7$ \\
\hline
\end{tabular}

$D_{\text {mean: }}$ Mean dose; $D_{\text {max }}$ : maximum dose; OC: optic chiasma; ON: optic nerve; PT: proton therapy;RION : radiation-induced optic neuropathy; Vx: the volume of the structure that receives $x$ Gy (RBE).

that is in patients treated for pituitary adenomas. For instance Noel et $\mathrm{al}^{13}$ reported an incidence rate of $2.2 \%$ of optic neuropathy after PT combined with photon therapy, when the chiasm was involved while Wenkel et $\mathrm{al}^{14}$ observed a higher rate of $6.5 \%$ in patients who received a Dmax of 56.4-62 Cobalt Gray Equivalent of combined photon/proton therapy on the optic apparatus. For PT only, Weber et $\mathrm{al}^{5}$ looked into the long-term outcomes of 222 patients with skull base low-grade chondrosarcoma and chordoma treated at the PSI with PBSPT and observed Grade 3 unilateral optic neuropathy and Grade 4 bilateral optic neuropathy in 2.3 and $0.9 \%$ of these patients, respectively. Similarly, the long-term results of the meningioma series of the same group, identified optic neuropathy in $7.7 \%$ of the patients. ${ }^{4}$ Of note, in our study we included only patients who received $\geq 45 \mathrm{~Gy}_{\mathrm{RBE}}$ to the $\mathrm{ON}$ (s) and/or OC and were thus of higher risk of presenting RION during their follow-up.

Furthermore, our results do not demonstrate a significant radiation dose and volume effect on the optic apparatus. There was a tendency for developing RION only when the OC received $>60$ Gy (V60) [hazard ratio (HR) 2.7, 95\% confidence interval (CI) $0.9-7.9 ; p=0.06]$ whereas other dose metrics (V45, V50 and V54) of the OC as well as all the dosimetric parameters of the ON were not associated with RION (Table 3). There are limited data on the dose-volume effect to the optic apparatus with some studies, treating with photons, indicating that delivering less than $50-60$ Gy to about $5-30 \%$ of the optic apparatus could reduce the risk of visual complications. ${ }^{15-17}$ Similarly, there is some evidence that Dmax to the optic apparatus could be clinically relevant in developing RION. Mayo et al, ${ }^{18}$ reviewing RION following proton and/or photon treatments, showed that there is a risk between 3 and $7 \%$ of developing RION in patients receiving Dmax 55-60 Gy Cobalt Gray Equivalent, increasing to $>7-20 \%$ for doses $>60$ Gy with normofractionation confirming earlier proton studies that RION is indeed dose-dependent. ${ }^{19,20}$ In our study, neither Dmax nor Dmean to the optic apparatus, which were less than $60 \mathrm{~Gy}_{\mathrm{RBE}}$, neither dose per fraction ( 2 Gy vs $1.8 \mathrm{~Gy}$ ) were significantly related to developing RION, with the prevalence of toxicity being $6.5 \%$, comparable to the QUANTEC data. ${ }^{16}$ Noteworthy, tumour abutting the optic apparatus was a significant risk factor $(p=$ 0.012), demonstrating that although high dose per se did not contribute to RION, tumour in close vicinity of the optic apparatus did. This observation could potentially be explained by the nerve/vascular damage to the optic apparatus as a result of compression and the consequential decrease in radiation tolerance. It could be argued that when the tumour is in close proximity to critical optic structures the former was under dosed, which would then most likely result in tumour progression locally. This, however, is not reflected in the reported 3- and 5 year OS of $99 \% \pm 1.4$ and $90.7 \% \pm 4.3$ respectively and the 3 and 5 year LC rates of $91.8 \% \pm 3.7$ and $84.3 \% \pm 5.1$ respectively. Even though there was a variety of tumour pathologies that were treated the majority (75\%) were patients diagnosed with a skull base chordoma or chondrosarcoma. This lack of proton dose metric-RION association in our series could potentially be explained by imbalances between the two RION and nonRION groups with respect to known and unknown baseline prognostic factors or statistical chance.

An important predictive factor in developing RION according to this study was age. More specifically patients $>70$ years-old had a significantly higher risk of presenting with optic neuropathy (HR 13.8 95\% CI $4.3-44.2 ;<0.0001$ ). Nevertheless, this finding should be interpreted cautiously since there were 
Table 4. Kaplan-Meier toxicity-free survival and univariate Cox regression analysis

\begin{tabular}{|c|c|c|c|c|c|}
\hline Variable & $\mathrm{N}$ & $\begin{array}{c}\text { Kaplan-Meier } \\
\text { toxicity-free survival } \\
(\%)\end{array}$ & $P$ & $\begin{array}{c}\text { Cox regression } \\
\mathrm{HR} \\
(95 \% \mathrm{CI})\end{array}$ & $P$ \\
\hline \multicolumn{6}{|l|}{ Age } \\
\hline$<70$ years & 208 & $95(92.0-98.1)$ & $<0.001$ & 1 (ref) & $<0.0001$ \\
\hline$\geq 70$ years & 8 & $50(25.0-100.0)$ & & $13.8(4.3-44.2)$ & \\
\hline \multicolumn{6}{|l|}{ Gender } \\
\hline Male & 105 & $96.1(92.4-99.9)$ & 0.11 & 1 (ref) & 0.13 \\
\hline Female & 111 & $90.7(85.4-96.4)$ & & $2.5(0.8-7.9)$ & \\
\hline \multicolumn{6}{|l|}{ Diabetes } \\
\hline No & 176 & $93.6(90-97.3)$ & 0.08 & 1 (ref) & 0.09 \\
\hline Yes & 17 & $82.4(66.1-100)$ & & $3.0(0.8-10.7)$ & \\
\hline \multicolumn{6}{|l|}{ Arterial hypertension } \\
\hline No & 142 & $97.2(94.5-99.9)$ & $<0.001$ & 1 (ref) & 0.0007 \\
\hline Yes & 51 & $79.3(68.7-91.7)$ & & $7.5(2.4-24.0)$ & \\
\hline \multicolumn{6}{|l|}{ Hypercholesterolemia } \\
\hline No & 177 & $93.7(90.2-97.4)$ & 0.07 & 1 (ref) & 0.08 \\
\hline Yes & 16 & $80.4(62.7-100)$ & & $3.1(0.9-11.1)$ & \\
\hline \multicolumn{6}{|l|}{ Smoking history } \\
\hline No & 120 & $90.6(85.5-96.1)$ & 0.26 & 1 (ref) & 0.27 \\
\hline Yes & 49 & $95.9(90.4-100)$ & & $0.4(0.1-1.9)$ & \\
\hline \multicolumn{6}{|l|}{ Histology } \\
\hline Chordoma \& Chondrosarcoma & 162 & $94.9(91.5-98.4)$ & 0.1 & 1 (ref) & 0.11 \\
\hline $\begin{array}{l}\text { Meningioma, ACC, Pituitary } \\
\text { Tumours }\end{array}$ & 54 & $88.5(80.3-97.6)$ & & $2.4(0.8-6.8)$ & \\
\hline \multicolumn{6}{|l|}{ GTV } \\
\hline$\leq 25.6 \mathrm{ml}$ & 108 & $91.3(85.9-96.9)$ & 0.28 & 1 (ref) & 0.29 \\
\hline$>25.6 \mathrm{ml}$ & 107 & $95.23(91.4-99.4)$ & & $0.6(0.2-1.7)$ & \\
\hline \multicolumn{6}{|l|}{ CTV } \\
\hline$\leq 59.6 \mathrm{ml}$ & 100 & $93.5(88.6-98.7)$ & 0.79 & 1 (ref) & 0.79 \\
\hline$>59.6 \mathrm{ml}$ & 100 & $93(88.1-98.1)$ & & $1.2(0.4-3.5)$ & \\
\hline \multicolumn{6}{|l|}{ PTV } \\
\hline$\leq 66.1 \mathrm{ml}$ & 97 & $92.3(86.9-98)$ & 0.97 & 1 (ref) & 0.97 \\
\hline$<66.1 \mathrm{ml}$ & 97 & $92.8(87.8-98.1)$ & & $1.0(0.3-2.8)$ & \\
\hline \multicolumn{6}{|l|}{ Number of surgeries prior to $\mathrm{PT}$} \\
\hline 1 & 100 & $91.6(86.2-97.4)$ & 0.61 & 1 (ref) & \\
\hline 2 & 69 & $95.6(90.9-100)$ & & $0.5(0.2-1.4)$ & 0.32 \\
\hline$\geq 3$ & 47 & $93.6(86.8-100)$ & & $0.8(0.2-3.1)$ & 0.75 \\
\hline \multicolumn{6}{|l|}{ Visual deficits prior to $\mathrm{PT}$} \\
\hline No & 167 & $92.1(88-96.3)$ & 0.19 & 1 (ref) & 0.22 \\
\hline Yes & 44 & $97.4(92.6-100)$ & & $0.3(0.04-2.1)$ & \\
\hline
\end{tabular}


Table 4. (Continued)

\begin{tabular}{|c|c|c|c|c|c|}
\hline Variable & $\mathbf{N}$ & $\begin{array}{c}\text { Kaplan-Meier } \\
\text { toxicity-free survival } \\
(\%)\end{array}$ & $P$ & $\begin{array}{c}\text { Cox regression } \\
\text { HR } \\
(95 \% \mathrm{CI})\end{array}$ & $P$ \\
\hline \multicolumn{6}{|c|}{$\begin{array}{l}\text { Tumour involvement of optic } \\
\text { apparatus at the beginning of PT }\end{array}$} \\
\hline No & 168 & $96.6(93.6-99.6)$ & 0.006 & 1 (ref) & 0.012 \\
\hline Yes & 48 & $86.4(78.4-95.1)$ & & $3.7(1.3-10.6)$ & \\
\hline \multicolumn{6}{|c|}{ ON inside target volume } \\
\hline No & 49 & $100(100-100)$ & 0.04 & 1 (ref) & \\
\hline Yes & 167 & $91.4(87.2-95.8)$ & & NA & \\
\hline \multicolumn{6}{|c|}{ OC inside target volume } \\
\hline No & 35 & $100(100-100)$ & 0.1 & 1 (ref) & \\
\hline Yes & 181 & $92.1(88.2-96.2)$ & & NA & \\
\hline \multicolumn{6}{|l|}{ Dmax ON } \\
\hline$\leq 59.5 \mathrm{~Gy} \mathrm{RBE}$ & 108 & $95.2(91.2-99.4)$ & 0.26 & 1 (ref) & 0.27 \\
\hline$>59.5 \mathrm{~Gy}$ RBE & 108 & $91.4(86.2-97)$ & & $1.9(0.6-5.5)$ & \\
\hline \multicolumn{6}{|l|}{ Dmean ON } \\
\hline$\leq 35.5 \mathrm{~Gy}$ RBE & 108 & $95.3(91.4-99.4)$ & 0.28 & 1 (ref) & 0.28 \\
\hline$>35.5 \mathrm{~Gy}$ RBE & 108 & $91.3(86-96.9)$ & & $1.8(0.6-5.4)$ & \\
\hline \multicolumn{6}{|l|}{ V45 ON } \\
\hline$\leq 0.43 \mathrm{ml}$ & 112 & $95.3(91.4-99.4)$ & 0.20 & 1 (ref) & 0.22 \\
\hline$>0.43 \mathrm{ml}$ & 104 & $91.2(85.8-96.9)$ & & $2.0(0.7-6.0)$ & \\
\hline \multicolumn{6}{|l|}{ V50 ON } \\
\hline$\leq 0.31 \mathrm{ml}$ & 109 & $95.3(91.3-99.4)$ & 0.26 & 1 (ref) & 0.27 \\
\hline$>0.31 \mathrm{ml}$ & 107 & $91.3(86-96.9)$ & & $1.9(0.6-5.5)$ & \\
\hline \multicolumn{6}{|l|}{ V54 ON } \\
\hline$\leq 0.17 \mathrm{ml}$ & 108 & $96.2(92.6-99.9)$ & 0.10 & 1 (ref) & 0.11 \\
\hline$>0.17 \mathrm{ml}$ & 108 & $90.5(85-96.3)$ & & $2.5(0.8-8.1)$ & \\
\hline \multicolumn{6}{|l|}{ V60 ON } \\
\hline$\leq 0 \mathrm{ml}$ & 137 & 95.5 (92-99.1) & 0.09 & 1 (ref) & 0.10 \\
\hline$>0 \mathrm{ml}$ & 79 & $89.5(82.8-96.7)$ & & $2.4(0.8-7.0)$ & \\
\hline \multicolumn{6}{|l|}{ Dmax OC } \\
\hline$\leq 58.8 \mathrm{~Gy}$ RBE & 108 & $94.3(89.9-98.8)$ & 0.59 & 1 (ref) & 0.59 \\
\hline$>58.8 \mathrm{~Gy}$ RBE & 108 & $92.4(87.4-97.6)$ & & $1.3(0.5-3.8)$ & \\
\hline \multicolumn{6}{|l|}{ Dmean OC } \\
\hline$\leq 50.5 \mathrm{~Gy} \mathrm{RBE}$ & 108 & $94.3(89.9-98.8)$ & 0.59 & 1 (ref) & 0.60 \\
\hline$>50.5 \mathrm{~Gy} \mathrm{RBE}$ & 108 & $92.4(87.4-97.6)$ & & $1.3(0.5-3.8)$ & \\
\hline \multicolumn{6}{|l|}{ V45 OC } \\
\hline$\leq 0.85 \mathrm{ml}$ & 109 & $93.5(88.9-98.3)$ & 0.97 & 1 (ref) & 0.97 \\
\hline$>0.85 \mathrm{ml}$ & 107 & $93.2(88.4-98.2)$ & & $1.0(0.4-2.9)$ & \\
\hline V50 OC & & & & & \\
\hline
\end{tabular}


Table 4. (Continued)

\begin{tabular}{|c|c|c|c|c|c|}
\hline Variable & $\mathrm{N}$ & $\begin{array}{c}\text { Kaplan-Meier } \\
\text { toxicity-free survival } \\
(\%)\end{array}$ & $P$ & $\begin{array}{c}\text { Cox regression } \\
\text { HR } \\
(95 \% \mathrm{CI})\end{array}$ & $P$ \\
\hline$\leq 0.59 \mathrm{ml}$ & 108 & $93.4(88.8-98.3)$ & 1.00 & $1(\mathrm{ref})$ & 1.00 \\
\hline$>0.59 \mathrm{ml}$ & 108 & $93.2(88.5-98.2)$ & & $1.0(0.4-2.9)$ & \\
\hline \multicolumn{6}{|l|}{ V54 OC } \\
\hline$\leq 0.29 \mathrm{ml}$ & 110 & $94.4(90.1-98.9)$ & 0.54 & 1 (ref) & 0.54 \\
\hline$>0.29 \mathrm{ml}$ & 106 & $92.2(87.2-97.6)$ & & $1.4(0.5-4)$ & \\
\hline \multicolumn{6}{|l|}{ V60 OC } \\
\hline $0 \mathrm{ml}$ & 168 & $95.2(92-98.5)$ & 0.05 & 1 (ref) & 0.06 \\
\hline$>0 \mathrm{ml}$ & 48 & $86.7(77.3-97.3)$ & & $2.7(0.9-7.9)$ & \\
\hline
\end{tabular}

$D_{\text {mean: }}$ Mean dose; ACC: adenocystic carcinoma; $D_{\text {max }}$ : maximum dose;HR, hazard ratio; OC: optic chiasma; ON: optic nerve;PT: proton therapy; Vx: the volume of the structure that receives $x$ Gy (RBE).

only eight patients aged $\geq 70$ years old. Conversely, Weber et $\mathrm{al}^{11}$ reported in the Boston series, employing a combination of protons and photons treatments, that younger age in that cohort was associated with late visual/ocular toxicity and this was explained by the longer follow-up in this patient group. On the other hand, a number of studies have shown that the risk of radiation-induced optic pathway injury is age dependent with increasing age being linked to an increased risk for developing RION. ${ }^{15,21,22}$

Another risk factor contributing to the development of optic neuropathy that was identified in this study was arterial hypertension (HR 7.5; 95\% CI 2.4-24.0, $p=0.0007$ ). It is important to note that in our study approximately $26 \%$ of the patients had been diagnosed with hypertension, while according to the latest statistics from the World Health Organisation the prevalence of hypertension in adults worldwide is estimated at $40 \%{ }^{23}$ Although there are inconsistent data on its role in optic nerve injury there is some evidence from photon studies that hypertensive patients are more likely to present with RION $^{15,24,25}$ even at "safe or acceptable" doses to the optic apparatus. ${ }^{26}$ The pathophysiological mechanism underlying this effect of hypertension, along with other vasculopathic risk factors, is the endothelial dysfunction and poor repairing mechanism of the arterioles hence the optic nerves are more susceptible to disruption of the blood circulation and secondary ischemia.

The limitations of this study stem mainly from its retrospective nature. First, it is remarkable that the majority of observed RIONs were high grade adverse events (Table 2). This suggests that infraclinical toxicity may have not been identifiable with a result of an under reporting of RIONs after high dose proton irradiation. Second, data collection, particularly concerning patient status/habits (smoking, hypertension, diabetes, and hypercholesterolemia) was limited in certain cases, potentially hampering the identification of an association between the different vasculopathic factors and RION. In addition, although ophthalmologic exams were routinely made for skull base tumours and meningioma patients, this was not the case for $\mathrm{H} \& \mathrm{~N}$ patients for whom ophthalmologic assessment was triggered by visual symptoms. As a result, the visual toxicity could have been under reported in approximately $7 \%$ of the overall cohort. Hence, future multicenter, collaborative studies would be able to recruit a larger number of patients prospectively and therefore identify more clearly potential risk factors. As of January 2018, PSI is capturing electronically (with a no opting out system) and prospectively all these vasculopathic factors for all new patients. Finally, since multiple statistical tests were conducted, false positive findings cannot be excluded. By applying Benjamini-Hochberg correction for multiple testing, age and arterial hypertension remained significantly associated with the toxicity-free survival. The other associations detected in this study need to be confirmed by further studies. The strengths of this study include its median long follow up time of 5.3 years. The prolonged follow-up period may be highly relevant. During RION, there is a latency time between exposure to radiation and optic complication onset. Thus, longer observation time may be necessary to reveal true RION rates. In addition, the large cohort size did not limit the statistical power to detect associations between RION and some of the clinical factors examined. Lastly, it is the first study reporting the risk of developing RION following proton therapy with PBS technique, irrespectively of the underlying tumour pathology, thus demonstrating the safety of this treatment.

In summary, the prevalence of RION remains very low in patients, who are at risk of presenting visual toxicity, treated with high dose radiation delivered with PBSPT for skull base or H\&N tumours. Potential risk factors in developing RION included age $\geq 70$ years, hypertension and tumour abutting the optic apparatus, in which cases it would be advised that the treatment plan should be carefully adjusted as clinically appropriate. 


\section{REFERENCES}

1. Hayreh SS. Blood supply of the optic nerve head and its role in optic atrophy, glaucoma, and oedema of the optic disc. $\mathrm{Br}$ J Ophthalmol 1969; 53: 721-48. doi: https:// doi.org/10.1136/bjo.53.11.721

2. Foulds WS. Visual disturbances in systemic disorders. optic neuropathy and systemic disease. Trans Ophthalmol Soc U K 1970; 89 125-46.

3. Demizu Y, Murakami M, Miyawaki D, Niwa Y, Akagi T, Sasaki R, et al. Analysis of vision loss caused by radiation-induced optic neuropathy after particle therapy for headand-neck and skull-base tumors adjacent to optic nerves. Int J Radiat Oncol Biol Phys 2009; 75: 1487-92. doi: https://doi.org/10. 1016/j.ijrobp.2008.12.068

4. Weber DC, Schneider R, Goitein G, Koch T, Ares C, Geismar JH, et al. Spot scanningbased proton therapy for intracranial meningioma: long-term results from the Paul Scherrer Institute. Int J Radiat Oncol Biol Phys 2012; 83: 865-71. doi: https://doi.org/ 10.1016/j.ijrobp.2011.08.027

5. Weber DC, Malyapa R, Albertini F, Bolsi A, Kliebsch U, Walser M, et al. Long term outcomes of patients with skull-base lowgrade chondrosarcoma and chordoma patients treated with pencil beam scanning proton therapy. Radiother Oncol 2016; 120: 169-74. doi: https://doi.org/10.1016/j.radonc. 2016.05.011

6. Lomax AJ, Pedroni E, Rutz H, Goitein G. The clinical potential of intensity modulated proton therapy. Z Med Phys 2004; 14: 147-52. doi: https://doi.org/10.1078/09393889-00217

7. Lomax AJ, Böhringer T, Bolsi A, Coray D, Emert F, Goitein G, et al. Treatment planning and verification of proton therapy using spot scanning: initial experiences. Med Phys 2004; 31: 3150-7. doi: https://doi.org/10.1118/1. 1779371

8. Pedroni E, Scheib S, Böhringer T, Coray A, Grossmann M, Lin S, et al. Experimental characterization and physical modelling of the dose distribution of scanned proton pencil beams. Phys Med Biol 2005; 50: 541-61. doi: https://doi.org/10.1088/00319155/50/3/011

9. Marks LB, Yorke ED, Jackson A, Ten Haken RK, Constine LS, Eisbruch A, et al. Use of normal tissue complication probability models in the clinic. Int J Radiat Oncol Biol Phys 2010; 76(3 Suppl): S10-S19. doi: https://doi.org/10.1016/j.ijrobp.2009.07. 1754
10. Placidi L, Bolsi A, Lomax AJ, Schneider RA, Malyapa R, Weber DC, et al. Effect of anatomic changes on pencil beam scanned proton dose distributions for cranial and extracranial tumors. Int J Radiat Oncol Biol Phys 2017; 97: 616-23. doi: https://doi.org/ 10.1016/j.ijrobp.2016.11.013

11. Weber DC, Chan AW, Lessell S, McIntyre JF, Goldberg SI, Bussiere MR, et al. Visual outcome of accelerated fractionated radiation for advanced sinonasal malignancies employing photons/protons. Radiother Oncol 2006; 81: 243-9. doi: https://doi.org/10.1016/ j.radonc.2006.09.009

12. Mackley HB, Reddy CA, Lee S-Y, Harnisch GA, Mayberg MR, Hamrahian AH, et al. Intensity-Modulated radiotherapy for pituitary adenomas: the preliminary report of the Cleveland clinic experience. Int J Radiat Oncol Biol Phys 2007; 67: 232-9. doi: https://doi.org/10.1016/j.ijrobp.2006.08.039

13. Noël G, Habrand JL, Mammar H, Pontvert D, Haie-Méder C, Hasboun D, et al. Combination of photon and proton radiation therapy for chordomas and chondrosarcomas of the skull base: the centre de Protonthérapie D'Orsay experience. Int J Radiat Oncol Biol Phys 2001; 51: 392-8. doi: https://doi.org/10.1016/S0360-3016(01) 01634-0

14. Wenkel E, Thornton AF, Finkelstein D, Adams J, Lyons S, De La Monte S, et al. Benign meningioma: partially resected, biopsied, and recurrent intracranial tumors treated with combined proton and photon radiotherapy. Int J Radiat Oncol Biol Phys 2000; 48: 1363-70. doi: https://doi.org/10. 1016/S0360-3016(00)01411-5

15. Bhandare N, Monroe AT, Morris CG, Bhatti MT, Mendenhall WM. Does altered fractionation influence the risk of radiationinduced optic neuropathy? Int J Radiat Oncol Biol Phys 2005; 62: 1070-7. doi: https://doi. org/10.1016/j.ijrobp.2004.12.009

16. Martel MK, Sandler HM, Cornblath WT, Marsh LH, Hazuka MB, Roa WH, et al. Dose-volume complication analysis for visual pathway structures of patients with advanced paranasal sinus tumors. Int J Radiat Oncol Biol Phys 1997; 38: 273-84. doi: https://doi. org/10.1016/S0360-3016(97)00029-1

17. Hoppe BS, Stegman LD, Zelefsky MJ, Rosenzweig KE, Wolden SL, Patel SG, et al. Treatment of nasal cavity and paranasal sinus cancer with modern radiotherapy techniques in the postoperative setting--the MSKCC experience. Int J Radiat Oncol Biol Phys 2007;
67: 691-702. doi: https://doi.org/10.1016/j. ijrobp.2006.09.023

18. Mayo C, Martel MK, Marks LB, Flickinger J, Nam J, Kirkpatrick J. Radiation dose-volume effects of optic nerves and chiasm. Int $J$ Radiat Oncol Biol Phys 2010; 76(3 Suppl): S28-S35. doi: https://doi.org/10.1016/j. ijrobp.2009.07.1753

19. Urie MM, Fullerton B, Tatsuzaki H, Birnbaum S, Suit HD, Convery K, et al. A dose response analysis of injury to cranial nerves and/or nuclei following proton beam radiation therapy. Int J Radiat Oncol Biol Phys 1992; 23: 27-39. doi: https://doi.org/10. 1016/0360-3016(92)90540-X

20. Habrand IL, Austin-Seymour M, Birnbaum S, Wray S, Carroll R, Munzenrider J, et al. Neurovisual outcome following proton radiation therapy. Int J Radiat Oncol Biol Phys 1989; 16: 1601-6. doi: https://doi.org/ 10.1016/0360-3016(89)90969-3

21. Danesh-Meyer HV. Radiation-Induced optic neuropathy. J Clin Neurosci 2008; 15: 95-100. doi: https://doi.org/10.1016/j.jocn.2007.09. 004

22. Parsons JT, Bova FJ, Fitzgerald CR, Mendenhall WM, Million RR. Radiation optic neuropathy after megavoltage externalbeam irradiation: analysis of Time-dose factors. Int J Radiat Oncol Biol Phys 1994; 30: 755-63. doi: https://doi.org/10.1016/03603016(94)90346-8

23. . World Health Organisation Global Health Observatory (GHO) data : Raised Blood Pressure Situation and trends. 2018. Available from: http://www.who.int/gho/ncd/ risk_factors/blood_pressure_prevalence_ text/en/.

24. Entezari M, Ramezani A, Pakravan M, Mahmoodi A, Hassanpour H, Yaseri M. Anterior ischemic optic neuropathy. Ophthalmology 2012; 119: 879-80. doi: https://doi.org/10.1016/j.ophtha.2011.12.022

25. Wang W, Yang H, Guo L, Su H, Wei S, Zhang $\mathrm{X}$. Radiation-Induced optic neuropathy following external beam radiation therapy for nasopharyngeal carcinoma: a retrospective case-control study. Mol Clin Oncol 2016; 4: 868-72. doi: https://doi.org/10.3892/mco. 2016.787

26. Doroslovacki P, Tamhankar MA, Liu GT, Shindler KS, Ying GS, Alonso-Basanta M Factors Associated with Occurrence of Radiation-induced Optic Neuropathy at "Safe" Radiation Dosage. Semin Ophthalmol 2017;: 1-8 